\title{
长白山林区森林/沼泽交错群落 的植物多样性*
}

\author{
牟长城 罗菊春 王襄平 韩景军 \\ ( 北京林业大学, 北京 100083)
}

\begin{abstract}
摘 要 本研究应用样带网格调查方法, 对森林/沼泽交错区上 6 种群落的植物多样性状况、优势种类 与分布以及交错区环境梯度进行了研究。结果表明:森林/沼泽交错区植物多样性具有沿着交错区环境 梯度逐渐增高的趋势; 发育成熟的交错群落具有最高的植物多样性, 且高于相对应的典型森林群落。由 于交错区群落存在着沼泽植物类群、森林类群以及交错区群落的优势种类群, 故发育成熟的交错区群落 种类较丰富,一些优势种种群数量为森林中的 5 倍。因为交错区的生境对于满足这些种类的生活史具 有重要作用。森林/沼泽交错群落的特征与交错区环境梯度以及两个植被类型的特征密切相关。

关键词森林/沼泽, 交错群落, 植物多样性, 长白山
\end{abstract}

Plant diversity of ecotone community between forest and marsh in Changbai Mountain/MU ChangCheng, LUO Ju-Chun , WANG Xiang-Ping, HAN Jing-Jun

Abstract Plant diversity of ecotone community between forest and marsh in Changbai Mountain was studied using whit net-check method throughout the ecotone, and the plant diversity, edge effects and their relation with ecotone enviromental gradient in two primary types of ecotone was also investigated, in order to reveal the characteristics and their forming mechanism and provide the theoretical foundation for the conversation and maintainance of plant diversity. .

The conclusion is that plant diversity of ecotone community between forest and marsh increases gradually along with the ecotone enviorment gradient in the Changbai Mountain. The mature community processes the highest diversity in the ecotone. It is also higher than that in the corresponding typical forest community. This kind of ecotone community is abundant in species because ecotones contain marsh plants, forest plants and ecotone's dominant species. The amount of some dominant species populations are five times as many as in the forest. So that edge effects exist in this ecotone. These characterristics of ecotone between forest and marsh are related closely with the ecological special properties of plants and the ecotone environmental gradient.

Key words forest and marsh ,ecotone community ,plant diversity ,Changbai Mountion

Author' s address Beijing Forestry University , Beijing 100083

生态交错区 (ecotone) 是指 相邻生态系统之间的过渡带。它具有由特定时间、空间尺度 所确定的一系列特征” [1]。一个群落交错区是两个或更多的不同群落之间的过渡。过渡区上 的群落即为交错区群落 ( ecotone community) ${ }^{[2]}$ 。

生态交错区内生境对满足许多生物生活史具有重要作用, 因此, 它往往是生物多样性发生 较高的地区 ${ }^{[3]}$ 。在生态交错区中存在这两个交迭群落的生物种类, 还包括反映群落交错区特 征通常被限制在交错区的特有种, 因此, 在交错区内生物种类以及一些种群密度有增加的趋势 即边缘效应 ( edge effect) ${ }^{[4]}$ 。这是生态交错区生物多样性的一般规律。湿地交错区可能具有 高的物种多样性，但对于特定的湿地边界物种多样性受各种因素的影响 ${ }^{[5]}$, 因此很难预测 ${ }^{[6]}$ 。 
Burk 在新英格兰 (USA) 内陆与淡水沼泽交错区中发现维管植物物种多样性在湿地与水域交 错区最低, 沼泽中部较高 ${ }^{[7]}$ 。在美国东北部几个潮汐沼泽取样调查得到了相类似的结论 ${ }^{[8]}$ 。 然而，在另一些情况下，陆地与湿地交错区可能仅有很少的种类。要回答湿地交错区生物多样 性问题，必须对整个区域 (即从陆地、湿地到水域) 以及湿地 - 陆地、湿地 - 水域交错区的生物 多样性加以研究 ${ }^{[9]}$,并且要结合物种生态特征与交错区生境梯度来分析生物多样性形成的机 理。为探讨森林/沼泽交错群落的生物多样性具有何种特殊规律性, 是否存在边缘效应与特有 种以及这些特性形成的机理, 我们对长白山林区不同类型的森林/沼泽交错群落的植物多样 性、边缘效应以及特有种进行了调查研究, 并结合交错区生境特征分析它们形成的机理, 从而 为维持与保护森林/沼泽交错区资源植物多样性提供理论依据。

\section{1 研究地区与研究方法}

\section{1 研究地区}

长白山林区沼泽类型是以修氏苔草 (Carex schmidtii) 为优势种, 燕尾风毛菊 (Saussurea serrata)、蚊子草 (filipendula palmata)、驴蹄草 (Caltha palustris)、地榆 (Sanguisorba officinalis) 等为 主要伴生种的群落。它们生长在季节性积水环境里, 有由这些植物死有机体形成厚达 $1 \mathrm{~m}$ 左 右的泥炭层，下部为 $\mathrm{A}$ 层和 $\mathrm{B}$ 层, 地下水位较高, 有潜育层。随地势增高, 地下水位降低, 积水 周期变短、积水减少、泥炭层变薄, 逐渐有森林成分侵入, 形成森林/沼泽交错群落。由于积水 深度的差异以及相邻森林群落的不同, 形成了森林/低位沼泽交错群落与森林/中位沼泽交错 群落两大类型。沿沼泽至森林方向前者依次出现 :1. 赤杨/沼泽交错群落 , 2. 赤杨、落叶松/沼 泽交错群落 3. 落叶松、白杹/沼泽交错群落;对应的典型森林群落为落叶松、白桦林群落。后 者依次出现 4. 柴桦/沼泽交错群落 5. 白桦/沼泽交错群落; ;. 山杨、山槐/沼泽交错群落, 相应 的典型森林群落为山杨、蒙古栎群落。

\section{2. 研究方法}

长白山区森林/沼泽交错区是地带性植被与隐域性植被之间的过渡带, 在空间尺度上相对 较小, 大气侯是一致的, 主要受局部地形、地势对水分再分配作用的影响, 因此, 外业调查适合 采用样带网格调查方法。具体调查时，我们在不同的森林/沼泽交错群落类型上,分别选择有 代表性的地段设置标准地, 宽 $20 \mathrm{~m}$, 长度依交错区宽度而定, 要包括典型沼泽、典型森林以及 整个交错区 (一般为几十、几百、几千米), 再分割为每 $30 \mathrm{~m}$ 长的一个个标准地, 再将标准地分 为 $5 \times 5 \mathrm{~m}^{2}$ 小样地 (即每个标准地有 24 个小样地)。在每个 $5 \times 5 \mathrm{~m}^{2}$ 小样地中心设置 $1 \times 2 \mathrm{~m}^{2}$ 小样方, 调查所有植物的种类和每个种的个体数量, 利用 Simpson 多样性指数公式:

$$
d=N(N-1) / \sum_{i=1}^{n} n_{i}\left(n_{i}-1\right)
$$

式中: $d$ 为多样性指数, $n$ 为种类数目, $n$ 为某个种个体数量, $N$ 为群落所有种个体数量。

计算群落的植物多样性指数, 揭示森林/沼泽交错群落植物多样性的变化规律, 并与典型 沼泽群落, 典型森林群落加以比较分析。通过交错区群落植物类群的划分以及种群数量的变 化分析森林/沼泽交错区的特有种与边缘效应。同时进行生境因子调查 (包括斑块大小、成 因、积水状况、土壤特征、地下水位、泥炭层厚度等因子), 并结合生境特征分析森林/沼泽交错 区群落植物多样性状况与边缘效应的形成机理。 
在沼泽到森林之间, 由于干湿度及微地形变化形成了一定的环境梯度, 依次出现了沼泽、

表 1 森林/低位沼泽交错区群落的植物多样性调查分析结果

Table 1 Investigating and analyzing data of ecotone community between forest and low swamp

\begin{tabular}{|c|c|c|c|c|c|c|c|c|}
\hline \multirow{3}{*}{$\begin{array}{c}\text { 群落类型 } \\
\text { community type }\end{array}$} & \multirow{3}{*}{$\begin{array}{c}\begin{array}{c}\text { 典型沼泽 } \\
\text { typical } \\
\text { swamp }\end{array} \\
\text { dz1 } \\
\text { 修氏苔草 }\end{array}$} & \multicolumn{5}{|c|}{$\begin{array}{c}\text { 森林/低位沼泽交错区群落 } \\
\text { ecotone community between forest and } \\
\text { low swamp }\end{array}$} & \multicolumn{2}{|c|}{$\begin{array}{c}\text { 典型森林群落 } \\
\text { typical forest }\end{array}$} \\
\hline & & $1 \sim 1$ & \multicolumn{2}{|c|}{$1 \sim 2$} & \multicolumn{2}{|c|}{$1 \sim 3$} & \multicolumn{2}{|c|}{$\mathrm{ds} 1$} \\
\hline & & 赤杨 & 赤杨 & 落叶松 & 落叶松 & 白桦 & 落叶松 & 白桦 \\
\hline 优势度 ( dominance ) & & 0.61 & 0.45 & 0.35 & 0.37 & 0.34 & 0.27 & 0.20 \\
\hline 距离 $(\mathrm{m})$ distance $(\mathrm{m})$ & $(60 \sim 30)$ & $(0 \sim 30)$ & $(30$ & $60)$ & $(60 \sim 90)$ & $(0 \sim 90)$ & $(160$ & $190)$ \\
\hline 林龄 (年) stand age ( year) & 20 & 35 & & & 50 & & & \\
\hline 物种数目 (species number) & 23 & 26 & & & 63 & 68 & & \\
\hline $\begin{array}{l}\text { 积水/林地 (\%) } \\
\text { water area/stand area (\%) }\end{array}$ & 50 & 40 & & & 15 & 27 & & \\
\hline $\begin{array}{l}\text { 泥炭厚度 }(\mathrm{cm}) \\
\text { thickness of sphagnum ( cm) }\end{array}$ & 55 & 45 & & & 9 & 28 & & \\
\hline $\begin{array}{l}\text { 地下水位 }(\mathrm{cm}) \\
\text { under ground water level }\end{array}$ & 9 & 25 & & & 76 & 47 & & \\
\hline 多样性指数 (diversity index) & 1.602 & 1.712 & & & 7. 325 & 2.708 & & \\
\hline
\end{tabular}

注 :dz1 典型低位沼泽群落 (typical ecotone community between forest and low swamp);1 1 赤杨/沼泽 ( alnus hirsuta/swamp);

２赤杨、落叶松/沼泽 ( alnus hirsuta \& larix olgensis/swamp) ; 1 3 落叶松、白桦/沼泽 ( larix olgensis \& betula platyphyl$\mathrm{la} /$ swamp) ; ds1 :典型森林群落 (落叶松、白桦群落) ( typical forest)

表 2 森林/中位沼泽交错区群落的植物多样性调查分析结果

Table 2 Investigating and analyzing data of ecotone community between forest and medial swamp

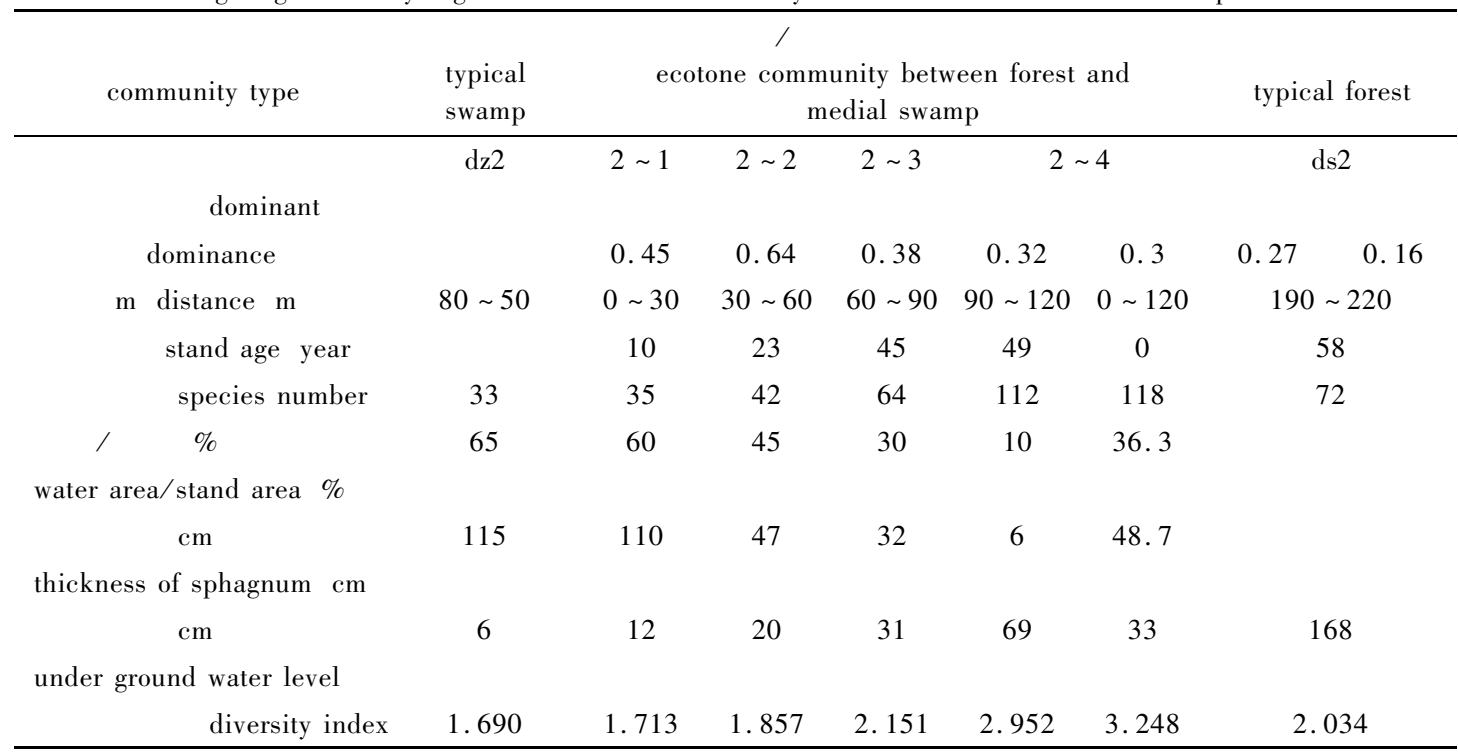

注 :dz2 典型中位沼泽群落 (typical ecotone community between forest and medial swamp);2 1 :柴桦/沼泽 (betula fruticosa/ swamp) ; 2 2 :白桦/沼泽 (林龄 20 年) ( betula platyphylla/swamp) ; 23 :白桦/沼泽 (林龄 40 年) (betula platyphylla/ swamp) 2 2 4 :山杨、山槐/沼泽 (populus davidiana \& maackia amurensis/swamp) ds2 典型森林群落(蒙古栎、山杨) ( typical forest)

木本沼泽、沼泽化森林、森林群落。长白山地区主要有中、低位沼泽到森林两类环境梯度 ,分布 着不同的植物群落类型, 表现出一定的植物多样性变化规律。调查分析结果数据见表 1 和表 
由表 1 、表 2 调查结果数据, 森林/低位沼泽交错区距离每增加 $30 \mathrm{~m}$ 植物多样性指数依次 为 : $1.712 、 2.372 、 7.325$;森林/中位沼泽交错区依次为: $1.713 、 1.857$ 、2.151、2.952。可知 :两 大类型交错区植物多样性指数均呈现同一变化趋势, 即随沼泽至森林的环境梯度变化植物多 样性有逐渐增加的趋势, 邻近沼泽交错区群落植物多样性最低, 远离沼泽植物多样性增高, 邻 近森林, 交错区群落植物多样性达到最高值, 且高于相对应的典型森林( 5.114、2.034)。森林 /沼泽交错区植物多样性指数 (2.708、3.248) 均高于典型沼泽群落 (1.602、1.690) ; 与典型森 林群落相比较则情况不同, 森林/低位沼泽交错区植物多样性低于典型森林群落, 森林/中位沼 泽交错区具有高于典型森林群落的植物多样性。

森林/沼泽交错群落的植物多样性主要是其生境与两个生物类群相互作用的结果。首先， 生境决定着群落的类型, 适应交错区生境的变化形成不同发育程度的交错群落,它们具有不同 种类植物所表现出的植物多样性。森林/沼泽交错区生境既有沼泽生境季节性积水特点, 又有 微域斑块 ( 类似于林地生境), 所以适应这两种生境, 就存在着沼泽植物类群与森林成分的类 群, 又由于交错区存在着环境梯度 (积水减轻、斑块扩大、泥炭层变薄、地下水位下降等) 以及 交错群落对生境的改造作用强度不同, 导致这两个植物类群的种类与数量发生了很大变化, 总 的变化趋势是沼泽植物种类逐渐减少 (如修氏苔草由 $400 \times 10^{4}$ 株 $/ \mathrm{hm}^{2} \rightarrow 200 \times 10^{4}$ 株 $/ \mathrm{hm}^{2} \rightarrow$ $100 \times 10^{4}$ 株 $/ \mathrm{hm}^{2}$ ), 而森林成分种类与数量则逐渐增加 (由几个种增至几十种)。森林/沼泽交 错群落发育初期以沼泽植物占绝对优势 (主要优势种修氏苔草、伴生种为燕尾风毛菊、地榆、 驴蹄草等), 森林成分的侵入则使交错区的植物多样性高于典型沼泽群落, 随生境的改善, 群 落发育程度的提高, 沼泽植物种类及数量虽有所减少, 但森林成分种类与数量则大大增加, 且 森林成分类群在种类、数量上多于沼泽植物类群, 结果势必导致交错区群落植物多样性逐渐增 高趋势。

2.2 不同类型森林/沼泽交错群落的植物多样性

长白山林区森林/沼泽交错群落主要有 6 种类型:(1)柴桦/沼泽交错群落;(2)赤杨/沼泽交 错群落; (3)赤杨、落叶松/沼泽交错群落; (4)落叶松、白桦/沼泽交错群落;5白哔/沼泽交错群 落; (6)山杨、山槐/沼泽交错群落。这些森林/沼泽交错群落沿着交错区环境梯度依次分布, 大 体上呈现一个以典型沼泽为分布中心, 以典型森林为终点的同心圆分布。这种分布是交错群 落适应环境梯度的结果。表 1 、表 2 不同森林/沼泽交错群落植物多样性调查结果说明:典型 沼泽群落仅 30 几个种, 群落植物多样性指数最低(1.69) ;柴㭫/沼泽交错群落略高于典型沼 泽群落 (1.72) 赤杨/沼泽交错群落, 赤杨、落叶松/沼泽交错群落和白桦/沼泽交错群落植物 多样性指数 ( 分别为 $2.04 、 2.372 、 1.977$ ) 相差不多, 且均高于前两者; 山杨、山槐/沼泽交错群 落植物多样性指数 (2.87) 较高, 高于相应的典型蒙古栎群落 (2.034) 落叶松、白桦/沼泽交错 群落植物多样性指数最高为 7.325 ,且高于典型森林群落( 以落叶松、白桦为优势种的混交林, 其指数为 5.114$)$ 。

不同类型森林/沼泽交错群落植物多样性的差异形成的主要原因是交错区群落与其生境 相互作用的结果。柴桦/沼泽交错群落以沼泽生境为主, 柴桦呈灌丛状零星分布在沼泽植被 上,柴桦侵入沼泽使该交错群落植物多样性略有增加;赤杨/沼泽交错群落、白桦/沼泽交错群 落生境相似, 为积水与微域玟块相混杂状态而存在, 两者所占的比重随环境梯度、群落对生境 改造作用 (生物排水、枯枝落叶堆积、土壤有机质及泥沙等沉积物积聚作用) 的加强而发生改 变, 使得积水逐渐减少, 微域斑块逐渐扩大, 交错区生境得以改善,适应变化了的生境出现了一 定数量的具有忍耐水湿、耐贫瘉能力的森林植物种类 ( $35 \sim 50$ 种) , 从而导致这两类交错群落 
植物多样性的提高, 这种群落对生境改造作用最终结果将是形成森林生境, 使森林/沼泽交错 群落演替为森林群落。落叶松、白桦/沼泽交错群落已接近这一阶段, 但仍有一定的沼泽生境 特征 (地下水位较高, 土壤长期为饱和含水状态等), 相应地存在一定数量沼泽植物种类, 同 时, 森林植物大量侵入使得这两类生物类群达到最大的相互渗透状态, 从而群落表现出最高的 植物多样性。

\section{3 森林/沼泽交错群落优势种及其分布规律}

长白山林区森林/沼泽交错群落具有优势种植物类群并表现出一定的分布规律性。乔木 层优势种有赤杨 (Alnus japonica)、白桦 (Betula platyphlla)、长白落叶松 (Larix olgensis)。赤杨 分布在交错区群落, 白桦、落叶松的种群密度高于相对应的典型森林群落 (落叶松、白桦混交 林) 2 3 倍; 灌木层中柴桦 (Betula fruticosa)、沼柳 (Salix brachypoda) 仅限于交错区群落, 柳叶 绣线菊 (Spiraea salicifolia)、蓝靛果忍冬 (Lonicera caerulea var. edulis) 种群密度为典型森林群 落的 5 倍, 黄花忍冬 (Lonicera chrysantha) 为 2 倍 草本层以修氏苔草等占优势。在交错区上还 存在一些其他群落所没有或少见的植物种类如 :水龙骨 (Polypodium virginianum) 、早熟禾 (Poa palustris)、独活 (Angelica dahurica)、藜芦 (Veratum nigrum)、景天 (Sedum spectadila)、土三七 (Sedum aizoon)、轮叶沙参 (Adeonphora tetraphylla)、轮叶百合 (Lilium disticun) 和宽叶苔草 ( Carex siderosticta $)$ 等种类。

森林/沼泽交错群落优势种的存在与分布是植物对交错区生境相适应及相互作用的结果。 交错区生境特征为积水与微域斑块相混杂状态而存在, 水湿、贫癐程度较沼泽地有所减弱, 但 仍不同于森林生境, 只有那些具有一定耐水湿、耐贫痊能力的植物才能适应该类生境; 交错区 优势种具有这种生态特性, 因此,才能在交错区内生存下来, 并形成较大数量的种群。但这些 种适应交错区生境的形式有所不同，如赤杨、白桦为深根性树种，它们的根系能够穿过泥炭层 着生在其下部有一定养分的 $\mathrm{A}$ 层内, 因此, 这 2 个种在交错区内生长尚好; 而落叶松适应该类 生境方式为浅根性, 依赖于不断形成的不定根, 使根系始终处于积水面之上, 因其生长受到限 制, 往往在交错区内长成小老头树。灌木、草本往往着生在微域斑块的上部或侧方以避免水湿 而得以生存。

\section{3}

结论

3. 1 森林/沼泽交错区植物多样性具有一定的变化规律。随着交错区环境梯度的变化、群落 发育程度的提高，自典型沼泽到典型森林方向森林/沼泽交错区植物多样性呈现逐步增高的趋 势, 邻近森林群落达最大值, 且高于典型森林群落, 但整个交错区植物多样性状况是高于典型 沼泽群落而低于或高于典型森林群落。这主要是由于隐域沼泽植被与森林植被种类组成特征 以及交错区生境异质性导致群落发育程度不均而决定的。

3.2 长白山林区森林/沼泽交错群落主要有 6 种类型即 :(1)柴桦/沼泽交错群落;(2)赤杨/沼 泽交错群落; (3)赤杨、落叶松/沼泽交错群落; (4)落叶松、白桦/沼泽交错群落; (5)白桦/沼泽交错 群落; (6)山杨、山槐/沼泽交错群落。这些交错群落植物多样性有所不同:柴桦/沼泽交错群落 植物多样性最低:赤杨/沼泽交错群落、赤杨、落叶松/沼泽交错群落、白桦/沼泽交错群落较低; 山杨、山槐/沼泽交错群落较高; 白桦、落叶松/沼泽交错群落植物多样性最高。这是群落适应 交错区生境的结果, 交错区环境梯度的存在, 导致形成了各种交错群落, 它们在种类组成以及 发育程度上有所不同，结果表现为不同的群落植物多样性。

3.3 森林/沼泽交错群落具有优势种类群表现出一定分布规律性。主要优势种有赤杨、白 
桦、落叶松、柴华、柳叶绣线菊、蓝靛果忍冬、修氏苔草、大叶樟、蚊子草等。这些种分布在交错 区不同的环境梯度上, 有的仅限于交错区群落才有, 有的种类在交错区上具有相当多的种群数 量, 这说明交错区生境对满足这些种类生活史具有重要作用, 也说明在交错区极端生境上植物 生态特性与分布极限能够明显表现出来。

根据上述研究结果, 长白山林区森林/沼泽交错区植物多样性有沿环境梯度逐渐增高的趋 势, 发育成熟的交错群落有最高的植物多样性, 且存在相当数量优势种生物类群。为维持与保 护这一交错区群落植物多样性, 必须防止破坏交错区生态环境及砍伐交错区森林, 使交错区群 落得以充分发育,才能保持森林/沼泽交错群落最高的植物多样性与物种遗传多样性。

\section{参 考 文 献}

1 Holland M M. SCOP/MAB technical consultations on landscape boundaries : report of a SCOPE/MAB workshop on ecotones. Biology International ,Special Issue. $1998,17: 47 \sim 106$

2 Clements F E. Research methods in ecology. Lincoln : University Publishing Company ,1905

3 Holland M M , Risser P G. The role of landscape boundaries in the management and restoration of changing environments : introduction. MAB Series, New York : Chapman. Hall Inc. 1991

4 Odum E P. Fundamentals of ecology (third edition). Hiladelphia : Saunders Company ,1971.

5 Patten B C, Jongensen S E, Gopal B et al. Ecotones : an edge approach to gene pool preservation and management in the diosphere, prospectus for a new scope program from the scientific advisory committee for wetlands and shallow continental water bodies. Athens ,1985

6 Van Der Marel E. On the establishment of plant community boundaries. Berichteder deutschem botanischen gessellschaft , $1976,89: 415 \sim 443$

7 Burk C L. A four year analysis of vegetation following an oil spillina freshwater marsh. Journal Of Applied Ecology 1977, 14 $515 \sim 522$

8 Senerchia-Nardone $\mathrm{P}$,Reilly A ,Holland M M. Floristic comparison of two tidal wetlands in the connecticut river estuary. Newsletter Of The Conneticut Botanical Society 1985, 13:6

9 Senerchia-Nardone P, Reilly A , Holland M M. Comparison of vascular plant zonation at Ionia island marsh and lord's cove marsh. In : Cooper J C ( ed. ) , Polgar fellowship reports of the Hudson River Estuarine Sanctuary Programm , New York State Department Of Enviromental Conversation ,1985, 1 35 